\title{
Prevalence and predictors of physical inactivity levels among Kenyan adults (18-69 years): an analysis of STEPS survey 2015
}

Muthoni Gichu ${ }^{1 *}$, Gershim Asiki ${ }^{2}$, Pamela Juma², Joseph Kibachio ${ }^{2,3}$, Catherine Kyobutungi ${ }^{2}$ and Elijah Ogola ${ }^{4}$

\begin{abstract}
Background: Physical inactivity accounts for more than 3 million deaths worldwide, and is implicated in causing $6 \%$ of coronary heart diseases, $7 \%$ of diabetes, and $10 \%$ of colon or breast cancer. Globally, research has shown that modifying four commonly shared risky behaviours, including poor nutrition, tobacco use, harmful use of alcohol, and physical inactivity, can reduce occurrence of non-communicable diseases (NCDs). Risk factor surveillance through population-based periodic surveys, has been identified as an effective strategy to inform public health interventions in NCD control. The stepwise approach to surveillance (STEPS) survey is one such initiative, and Kenya carried out its first survey in 2015. This study sought to describe the physical inactivity risk factors from the findings of the Kenya STEPS survey.
\end{abstract}

Methods: This study employed countrywide representative survey administered between April and June 2015. A three stage cluster sampling design was used to select clusters, households and eligible individuals. All adults between 18 and 69 years in selected households were eligible. Data on demographic, behavioural, and biochemical characteristics were collected. Prevalence of physical inactivity was computed. Logistic regression used to explore factors associated with physical inactivity.

Results: A total of 4500 individuals consented to participate from eligible 6000 households. The mean age was 40.5 (39.9-41.1) years, with 51.3\% of the respondents being female. Overall 346 (7.7\%) of respondents were classified as physically inactive. Physical inactivity was associated with female gender, middle age (30-49 years), and increasing level of education, increasing wealth index and low levels of High Density Lipoproteins (HDL).

Conclusion: A modest prevalence of physical inactivity slightly higher than in neighbouring countries was found in this study. Gender, age, education level and wealth index are evident areas that predict physical inactivity which can be focused on to develop programs that would work towards reducing physical inactivity among adults in Kenya.

Keywords: Physical inactivity, Non-communicable diseases, Kenya

\footnotetext{
* Correspondence: muthonigichu@gmail.com

'Division of Non Communicable Diseases, Ministry of Health, Nairobi, Kenya

Full list of author information is available at the end of the article
}

(c) The Author(s). 2018 Open Access This article is distributed under the terms of the Creative Commons Attribution 4.0 International License (http://creativecommons.org/licenses/by/4.0/), which permits unrestricted use, distribution, and reproduction in any medium, provided you give appropriate credit to the original author(s) and the source, provide a link to the Creative Commons license, and indicate if changes were made. The Creative Commons Public Domain Dedication waiver (http://creativecommons.org/publicdomain/zero/1.0/) applies to the data made available in this article, unless otherwise stated. 


\section{Background}

Physical inactivity has been identified as the fourth leading risk factor for global mortality causing approximately 3 million preventable deaths worldwide [1]. Epidemiological research shows that 15-20\% of the overall risk for coronary heart disease, type 2 diabetes, colon cancer, breast cancer is due to physical inactivity, which also leads to fractured hips in older persons [2]. Physical inactivity causes $6 \%$ of the burden of disease from coronary heart disease, $30 \%$ of ischemic heart disease, $7 \%$ of type 2 diabetes, $10 \%$ of breast cancer, and $10 \%$ of colon cancer $[3,4]$. Examination of meta-analyses, systematic reviews, and pooled analyses performed by the 2018 Physical Activity Guidelines Advisory Committee of the US Department of Health and Human Services confirms significant health benefits due to physical activity for different non-communicable diseases (NCDs) [5].

The economic consequences of physical inactivity on healthcare cost are substantial mainly due to indirect costs such as the value of reduced economic output because of illness, disease related work disabilities and premature death [6-9]. Mortality rates from NCDs increase with increasing body weight, and are markedly increased when individuals are classified as obese [10]. Regular physical activity is a protective factor against unhealthy weight gain $[5,10]$. For these reasons, the World Health Organization (WHO) passed resolution WHA55.23 in 2002 [11] and formulated a global strategy to address physical activity and health in 2004 [12]. Subsequently, a $10 \%$ relative reduction in prevalence of insufficient physical activity was set as one of nine goals to be met by 2020 in the Global Action Plan 2013-2020 for NCDs [13].

Regrettably, 'physical activity transition' referring to resultant decline in physical activity levels, coupled with increasing sedentary behaviours over time [14, 15], is affecting younger people, including children and the youth, leading to negative health consequences such as obesity particularly among urban residents [16-18]. According to the Global School Health Survey of 2003 conducted among students aged 13 to 15 years in Kenya, only $11.1 \%$ met the required regular physical activity threshold of at least 60 min per day and up 40.9\% were reported to have sedentary habits [19]. The 2016 Kenya Report Card indicated that only half of Kenyan children and adolescents were engaging in sufficient levels of physical activity [20]. Although these surveys used different methods, the low levels may have contributed to the observed increase in overweight and obesity among the children with $4 \%$ of rural and $21 \%$ of Kenyan urban children being overweight or obese [21]. The increase has been associated with demographic and social changes such as globalization, urbanization, aging population and adoption of unhealthy lifestyles [22] that is especially relevant to developing countries like Kenya.
Recognizing the importance of NCDs, the Ministry of Health in Kenya published the National Strategy for the Prevention and Control of NCDs for 2015-2020 [23]. While this strategy mentions promotion of physical activity as one of the objectives where in there are no specific policies and interventions in place to address the situation despite the declining levels of physical activity, and the associated increase in obesity and overweight among the adults and children [23]. Moreover, there is limited population-based data to inform the much needed policies and interventions. The STEPs survey conducted in 2015 generated national level data on NCDs risk factors including physical inactivity thus provided an opportunity to profile population level factors to inform policy towards the reduction of NCDs as well as promote physical activity.

\section{Methods}

We use data from the STEPs Kenya 2015 survey, a nationally representative household survey conducted between April and June 2015 as detailed elsewhere [24].

Data on physical activity was collected using the Global Physical Activity Questionnaire (GPAQ) as a self-report [25]. This tool was developed by the WHO, and has been validated for physical activity surveillance in developing countries. Physical activity was determined from the amount of time being physically active in three domains; transport, at work and during leisure time. Through a self-report questionnaire participants were asked about the intensity of their physical activity (vigorous or moderate) guided by a show card (a visual aid demonstrating various activities by intensity) for work and leisure, inclusion of ten continuous minutes spent walking or cycling for transport, number of days they performed these activities in a typical week and amount of time spent on each activity on a typical day [24]. Data collection was administered using a Personal Digital Assistant (PDA) loaded with eSTEPS software. The system was designed to allow PDA to show only a question and all its possible answers at a time in one screen view, and also provided various filters, skips and validation procedures.

\section{Statistical analysis}

In this study, physical inactivity was defined as obtaining less than $150 \mathrm{~min}$ of moderate intensity physical activity throughout the week or less than 75 min of vigorous intensity physical activity throughout the week or less than an equivalent combination of moderate- and vigorous intensity derived from WHO definition of physical activity [11]. The proportion of participants who met this definition was estimated overall and according to a variety of participant characteristics. The independent variables used in this study were in three categories: demographic (sex, age, marital status, highest level of education, occupation, residence, wealth status), behavioural (tobacco use and alcohol 
consumption), and physical and biochemical measurements (waist circumference, blood pressure and cholesterol). Men with waist circumference of $>104 \mathrm{~cm}$ or women with waist circumference of $88 \mathrm{~cm}$ were classified as centrally obese, Waist hip ratio of 0.85 among women and 0.90 men was considered as obesity risk. Systolic blood pressure $>140$ and diastolic pressure $>90$ were categorized as hypertension. Low HDL was defined as $<1.03 \mathrm{mmol} / \mathrm{L}$ among men and $<1.29 \mathrm{mmol} / \mathrm{L}$ among women.

Logistic regression analyses were used to compute adjusted odds ratios for each exposure variable while controlling for all the other variables (confounders) in the model. $P$-values of less than 0.05 were considered significant. The analysis was done using STATA software, version 14.

\section{Results}

\section{Characteristics of study participants}

In total 6000 adults were invited to participate in this study, 4500 (75\%) completed the survey and 4484 (74.4\%) had no missing data. Table 1 presents the characteristics of the sample. The study participants were adults aged 18 to 69 years with a mean age of $40.5(39.9-41.1)$ years, with slightly fewer males than females (48.7\% versus $51.3 \%$ ). Most respondents $(>85 \%$ ) had some education (mainly secondary), were rural residents (62\%), employed (80\%) and married (65\%).

\section{Prevalence of physical inactivity}

A total of 346 (7.7\%) of the respondents were classified as physically inactive. Physical inactivity was more prevalent among those in middle age (30-49 years), among those with no formal education, in the urban areas, among students, non-paid/- volunteers, unemployed, and single adults (Table 1).

\section{Factors associated with physical inactivity}

Results from the multivariable analysis indicated women were 1.72 times more likely to be physically inactive than men. Physical inactivity was twofold higher among those aged 30-39 years, and 40-49 years compared to those aged 50-69 years, and was 2-5 odds higher among those with education compared to those with no formal education. Individuals self-reporting the middle wealth quintile were three times more likely to be physically inactive than those in the poorest and second wealth quintile. Individuals with low level of HDL had double odds of being physically inactive. Being in the richest wealth quintile had lower odds (0.39) of physical inactivity compared to those within the lowest level of wealth quintile. There was borderline association of physical inactivity with rural residence (OR $=1.6195 \%$ CI $[0.96$, 2.69], central obesity $(\mathrm{OR}=1.5395 \%$ CI $[0.99,2.35])$ and lower odds with hypertension $(\mathrm{OR}=0.67,95 \% \mathrm{CI}$ $(0.44,1.02)$ - Table 2.
Table 1 Demographic characteristics and physical inactivity prevalence among adults in the Kenya STEPS survey 2015

\begin{tabular}{|c|c|c|c|}
\hline Characteristics & Total & $(\%)$ & Physically Inactive (\%) \\
\hline \multicolumn{4}{|l|}{ Sex } \\
\hline Male & 2186 & 48.75 & $175(8.0)$ \\
\hline Female & 2298 & 51.25 & $172(7.5)$ \\
\hline \multicolumn{4}{|l|}{ Age groups } \\
\hline $18-29$ & 2062 & 45.99 & $193(9.4)$ \\
\hline $30-39$ & 1045 & 23.31 & $57(5.5)$ \\
\hline $40-49$ & 695 & 15.50 & $37(5.4)$ \\
\hline $50-59$ & 443 & 9.88 & $32(7.3)$ \\
\hline $60-69$ & 239 & 5.33 & $26(10.9)$ \\
\hline \multicolumn{4}{|l|}{ Education level } \\
\hline No formal education & 563 & 12.56 & $70(12.5)$ \\
\hline Primary incomplete & 1044 & 23.28 & $59(5.7)$ \\
\hline Primary complete & 1000 & 22.30 & $62(6.2)$ \\
\hline Secondary and above & 1877 & 41.86 & $155(8.2)$ \\
\hline \multicolumn{4}{|l|}{ Residence } \\
\hline Rural & 2776 & 61.91 & $167(6.0)$ \\
\hline Urban & 1708 & 38.09 & $179(10.5)$ \\
\hline \multicolumn{4}{|l|}{ Occupation } \\
\hline Unemployed & 493 & 10.99 & $54(10.9)$ \\
\hline Employed & 936 & 20.87 & $80(8.6)$ \\
\hline Homemaker & 981 & 21.88 & $81(8.3)$ \\
\hline Non-paid/volunteer & 19 & 0.42 & $2(10.7)$ \\
\hline Self-employed & 1749 & 39.01 & $90(5.2)$ \\
\hline Student & 306 & 6.82 & $39(12.7)$ \\
\hline \multicolumn{4}{|l|}{ Marital status } \\
\hline Not married & 1039 & 23.17 & $103(10)$ \\
\hline Married & 2938 & 65.52 & $200(6.8)$ \\
\hline Formerly married & 507 & 11.31 & $43(8.5)$ \\
\hline
\end{tabular}

\section{Discussion}

Using data from a nationally representative survey in Kenya, the prevalence of physical inactivity was found to be $7.7 \%$, similar to that reported in other sub-Saharan Africa (SSA) countries such as Burkina Faso (7.8\%), Malawi $(8.4 \%)$ and Ghana (8.8\%) [26]. This was significantly higher than in the neighbouring country, Uganda with $4.3 \%$ prevalence of physical inactivity reported in the recent STEPS survey [27]. South Africa (44.7\%), Mauritania (52.6\%) and Swaziland (49.1\%) reported higher prevalence of physical inactivity [26]. These results support the notion that prevalence of physical inactivity is a function of country's income and is usually high in developed countries and low in less developed and underdeveloped countries [28]. However, this differs from the STEPs surveys undertaken in same countries with differing prevalence, Burkina Faso (17.7\%), Malawi (9.5\%), Ghana (85.7\%), 
Table 2 Predictors of physical inactivity among adults aged 18-69 years in Kenya (2015)

\begin{tabular}{|c|c|c|}
\hline Predictor & Adjusted Odds Ratio (95\% Cl) & $\mathrm{p}$-value \\
\hline \multicolumn{3}{|l|}{ Gender } \\
\hline Male & 1.00 & \\
\hline Female & $1.72(1.15,2.56)$ & $0.008^{*}$ \\
\hline \multicolumn{3}{|l|}{ Age group } \\
\hline $50-69$ & 1.00 & \\
\hline $18-29$ & $1.17(0.70,1.98)$ & 0.550 \\
\hline $30-39$ & $2.04(1.12,3.73)$ & $0.021^{*}$ \\
\hline $40-49$ & $1.90(1.01,3.61)$ & $0.048^{*}$ \\
\hline \multicolumn{3}{|l|}{ Residence } \\
\hline Urban & 1.00 & \\
\hline Rural & $1.61(0.96,2.69)$ & 0.069 \\
\hline \multicolumn{3}{|l|}{ Education level } \\
\hline No formal education & 1.00 & \\
\hline Primary incomplete & $2.54(1.38,4.67)$ & $0.003^{*}$ \\
\hline Primary complete & $5.33(2.54,11.19)$ & $0.000^{*}$ \\
\hline Secondary and above & $2.99(1.60,5.60)$ & $0.001^{*}$ \\
\hline \multicolumn{3}{|l|}{ Wealth band } \\
\hline Poorest & 1.00 & \\
\hline Second & $1.23(0.63,2.39)$ & 0.550 \\
\hline Middle & $2.94(1.15,7.54)$ & $0.025^{*}$ \\
\hline Fourth & $0.86(0.42,1.75)$ & 0.672 \\
\hline Richest & $0.39(0.18,0.84)$ & $0.016^{*}$ \\
\hline \multicolumn{3}{|l|}{ Tobacco use } \\
\hline No & 1.00 & \\
\hline Yes & $1.32(0.75,2.34)$ & 0.334 \\
\hline \multicolumn{3}{|l|}{ Weekly alcohol drinking } \\
\hline No alcohol & 1.00 & \\
\hline Daily & $1.97(0.47,8.23)$ & 0.351 \\
\hline 3 or more days & $0.80(0.36,1.78)$ & 0.581 \\
\hline Less than 3 days & $0.93(0.60,1.45)$ & 0.753 \\
\hline \multicolumn{3}{|l|}{ Hypertension } \\
\hline No & 1.00 & \\
\hline Yes & $0.67(0.44,1.02)$ & 0.064 \\
\hline \multicolumn{3}{|l|}{ Waist circumference } \\
\hline Normal & 1.00 & \\
\hline Centrally obese & $0.83(0.52,1.31)$ & 0.417 \\
\hline \multicolumn{3}{|l|}{ Waist Hip Ratio } \\
\hline Normal & 1.00 & \\
\hline Centrally obese & $1.53(0.99,2.35)$ & 0.055 \\
\hline \multicolumn{3}{|l|}{ HDL cholesterol } \\
\hline Normal & 1.00 & \\
\hline Low & $1.83(1.09,3.08)$ & $0.023^{*}$ \\
\hline
\end{tabular}

*Significant at $p<0.05$
Mauritania (50.7\%) and Swaziland (15.3\%) [29]. This could be attributed to the differences in the methodology used between the STEPs survey and the studies. The estimated global adult physical inactivity prevalence in 2008 was $31 \%$ [29]. Although the prevalence of physical inactivity is not alarming in Kenya yet, it is likely to increase without timely policy put in place. Factors associated with physical inactivity were identified.

In the Kenyan population the factors significantly associated with physical inactivity in the analyses undertaken include: female gender, middle age 30-49 years, formal education, middle wealth and low levels of HDL.

Similar to a number of other studies [30-34], women were more likely to be physically inactive than men in this study. To a large extent, men tend to engage more in vigorous and moderately intense sports activities than women $(83.7 \%$ versus $16.3 \%)$ and this could be attributed to social-cultural factors including gender roles. More specifically, these factors include the dominance of work and family responsibilities on women, social norms that permit higher levels of PA in men especially in work domains, lack of social support for women to be active, social isolation, environmental constraints, economics, and low levels of personal knowledge and motivation that limit physical activity among women [35-37].

In this study nearly two thirds of the sample classified as physically inactive were middle aged adults between 30 and 49 years. Micklesfield et al. made a similar observation in South Africa where $43-50 \%$ of physically inactive were young adults [38]. Young people in SSA engage more in light and incidental moderate-intensity physical activity during domestic chores and active transportation while the older people make conscious decisions to exercise for health benefits [39]. This finding is not surprising given the potential increased risk perception of NCDs among older people which may lead to greater interest in engaging in preventive measures such as physical activity.

Contrary to observations by Benjamin and Linda in the United States of America (USA) [40], physical inactivity increased with level of education in our study. This finding could be explained as a result of the low priority accorded to physical activities in schools as revealed in a study among Kenyan school children in 2014, which showed that children were spending a considerable amount of time sitting in class with light intensity physical activity due to more emphasis on grades compromising the quality and quantity of physical education and most children used motorised transport to and from school [41].

Being in the middle wealth quintile was associated with higher levels of physical inactivity similar to what was observed in Vietnam [34]. This could be due to physical inactivity arising from using motorized transport and a more sedentary work environment for the middle class. Individuals in the richest wealth quintile were less 
physically inactive than the other wealth categories; this may be due to their additional resources to access and utilize leisure time physical activity opportunities.

Physical inactivity was associated with low levels of HDL similar to other research [42]. This result was to be expected as physical activity is known to increase levels of HDL [42-44].

There were borderline associations between physical inactivity and rural residence, and between physical inactivity and central obesity. The association of physical inactivity with rural residence in Kenya is surprising because previous publications indicated physical inactivity to be higher among urban than rural residents in SSA [44-47]. The Kenyan situation here was in agreement with the observations by Wilcox et al. in USA [48], where rural residents were less physically active compared to urban residents. This is explained by limited opportunities for leisure related physical activities in the rural areas despite the engagement in physical activity in other domains of work and transport. The borderline association between physical inactivity and central obesity also observed in our study is consistent with the report of Kruger et al. in South Africa, however there may be other contributing factors like the difference in development [49].

Low- and middle-income countries such as Kenya contribute almost three quarters of global NCD deaths, $82 \%$ of all NCD premature deaths (below age of 70 years) $[10,50]$ and the highest number of health years lost/disability adjusted life years worldwide [51]. With the projected rise in the burden of NCDs in low- and middle-income settings $[10,50]$, addressing physical inactivity which is a major risk factor for NCDs in these settings will be crucial in meeting the global target of $10 \%$ relative reduction in the prevalence of insufficient physical activity [13]. In Kenya, the objectives promote physical activity stated in the National Strategy for the Prevention and Control of NCDs for 2015-2020 [23] should be operationalized towards this global goal.

This study had some limitations. In the STEPwise survey physical activity was self-reported. Previous studies on the validity of self-reported measure of physical activity suggest that reliability of self-report is dependent on factors such as the type of questionnaire used, participants' age and the type, duration and intensity of physical activities measured by self-reporting $[52,53]$. In addition, there could be a variance in the validity of the self-report due to ethnicity, language, education and health status [54-56]. However, the Global Physical Activity Questionnaire used in the WHO STEPwise survey has been validated and found suitable and acceptable instrument for monitoring physical activity in population health surveillance systems in developing countries [25].

\section{Conclusion}

This study has for the first time reported the country-wide prevalence of physical inactivity among adults aged 1864 years in Kenya and identified population groups to be targeted for interventions. In order to increase physical activity at population level and thus reduce physical inactivity, interventions should be targeted to women, people within middle age, the middle class, and to post-secondary students in schools. Physical activity in Kenya which is mostly work related is more often than not viewed as a means to have work completed and the link to health is missing. There is need to keep in mind that this self-report may be subjective. Among the four major risk factors for NCDs, physical inactivity is the only risk factor with no policy for promotion of physical activity. This paper provides relevant information for health policymakers to establish interventions to increase physical activity levels among risk groups identified as well as among the general population.

\section{Abbreviations}

HDL: High Density Lipoproteins; NCDs: Non-Communicable Diseases;

SSA: Sub-Saharan Africa; USA: United States of America; WHO: World Health Organisation

\section{Acknowledgements \\ We would like to thank all the individuals and organizations that provided technical support for the design and implementation of the main survey. The CORE funding for the main survey was provided by World Bank, WHO, AstraZeneca and $\mathrm{MOH} / \mathrm{CDC}$. Authors are also grateful to the data collection and analysis team led by the Ministry of Health, WHO and Kenya National Bureau of statistics, Kenya Medical Research Institute (KEMRI) and African Institute for Health and Development (AIHD).}

\section{Funding}

Analysis time and publication costs were funded by the International Development Research Center (IDRC) (grant \# 107209-001).

\section{Availability of data and materials}

Study materials and de-identified data that support the findings in this study are available by contacting Gladwell Gathecha at the Ministry of Health Kenya at gladwellgathecha@gmail.com

\section{About this supplement}

This article has been published as part of BMC Public Health Volume 18 Supplement 3, 2018: Special issue from national survey on NCD risk factors in Kenya. The full contents of the supplement are available online at https:// bmcpublichealth.biomedcentral.com/articles/supplements/volume-18supplement-3.

\section{Authors' contributions}

MG conceived the study. MG and PJ wrote the analysis plan. MG and GA conducted the literature review and wrote the first draft manuscript. EM did the analysis. CK contributed to the literature review. RW, AK and GG reviewed the draft manuscript, provided input, critical comments. MG finalized the manuscript which was subsequently approved by all authors.

\section{Ethics approval and consent to participate}

Ethics review for the study protocol was conducted and approved by Kenya Medical Research Institute's Ethics Review Committee (SSC No. 2607). Study respondents were provided with information in a language easy to understand, and an opportunity to determine if they wanted to participate or not and both verbal and written consents were obtained before participation. 


\section{Consent for publication}

Not applicable.

\section{Competing interests}

The authors declare that they have no competing interests.

\section{Publisher's Note}

Springer Nature remains neutral with regard to jurisdictional claims in published maps and institutional affiliations.

\section{Author details}

${ }^{1}$ Division of Non Communicable Diseases, Ministry of Health, Nairobi, Kenya. ${ }^{2}$ The Institute of Global Health, Faculty of Medicine, University of Geneva (UNIGE), Geneva, Switzerland. ${ }^{3}$ African Population and Health Research Center, Nairobi, Kenya. ${ }^{4}$ Clinical Medicine, University of Nairobi, Nairobi, Kenya.

\section{Published: 7 November 2018}

\section{References}

1. World Health Organization (WHO). Global Health risks-mortality and burden of disease attributable to selected major risks 2009. Geneva: WHO; 2009. Available http://www.who.int/healthinfo/global_burden_disease/global_ health_risks/en/.

2. Oja P, Borms J. Health enhancing physical activity: an introduction. Perspect . The multidisciplinary ser of Phys Educ and Sport Sci. 2004;6:21-7.

3. Lee IM, Shiroma EJ, Lobelo F, Puska P, Blair SN, Katzmarzyk PT. Lancet physical activity series working group. Effect of physical inactivity on major non-communicable diseases worldwide: an analysis of burden of disease and life expectancy. Lancet. 2012;380(9838):219-29.

4. Kyu HH, Bachman VF, Alexander LT, Mumford JE, Afshin A, Estep K, Veerman $J$, Delwiche K, lannarone ML, Moyer ML, Cercy K. Physical activity and risk of breast cancer, colon cancer, diabetes, ischemic heart disease, and ischemic stroke events: systematic review and dose-response meta-analysis for the global burden of disease study 2013. BMJ. 2016;354:13857.

5. 2018 Physical Activity Guidelines Advisory Committee. 2018 Physical activity guidelines advisory committee scientific report. Washington: Department of Health and Human Services; 2018.

6. Lee BY, Adam A, Zenkov E, Hertenstein D, Ferguson MC, Wang PI, Wong MS, Wedlock P, Nyathi S, Gittelsohn J, Falah-Fini S. Modeling the economic and health impact of increasing children's physical activity in the United States. Health Aff. 2017;36(5):902-8.

7. Sørensen J, Horsted C, Andersen LB. Modellering af potentielle sundhedsøkonomiske konsekvenser ved øget fysiskaktivitet i den voksne befolkning [models of potential health economic consequences by increased physical activity in the adult population]. Odense: Syddansk Universitet: 2005.

8. Ding D, Kolbe-Alexander T, Nguyen B, Katzmarzyk PT, Pratt M, Lawson KD. The economic burden of physical inactivity: a systematic review and critical appraisal. Br J Sports Med. 2017;51:1392-409.

9. Ding D, Lawson KD, Kolbe-Alexander TL, Finkelstein EA, Katzmarzyk PT, Van Mechelen W, Pratt M. Lancet physical activity series 2 executive committee. The economic burden of physical inactivity: a global analysis of major noncommunicable diseases. Lancet. 2016:388(10051):1311-24.

10. World Health Organisation. Global status report on noncommunicable diseases 2014. Geneva: WHO; 2015. Available: http://www.who.int/nmh/ publications/ncd-status-report-2014/en/. Accessed 9 May 2017.

11. World Health Organisation. WHA 55.232002 resolution: WHO; 2002. Available http://apps.who.int/gb/archive/pdf_files/WHA55/ewha5523. pdf?ua=1. Accessed 9 May 2017.

12. WHO. Global strategy on diet, physical activity and health. Geneva: WHO; 2004. Available: http://apps.who.int/iris/bitstream/handle/10665/43035/ 9241592222_eng.pdf?sequence=1. Accessed 9 May 2017.

13. WHO. Global action plan for the prevention and control of NCDs 2013-2020 WHO; 2013. Available: http://www.who.int/nmh/publications/en/. Accessed 9 May 2017.

14. Katzmarzyk PT, Mason C. The physical activity transition. J Phys Act Health. 2009;6(3):269-80.

15. Omram AR. The epidemiologic transition theory. A preliminary update. J Trop Pediatr. 1983;29(6):305-16.
16. Wang $Y$, Lim $H$. The global childhood obesity epidemic and the association between socio-economic status and childhood obesity. Int Rev Psychiatry. 2012;24(3):176-88

17. Hill JO, Wyatt HR. Role of physical activity in preventing and treating obesity. J Appl Physiol. 2005;99(2):765-70.

18. Abarca-Gómez L, Abdeen ZA, Hamid ZA, Abu-Rmeileh NM, Acosta-Cazares B, Acuin C, Adams RJ, Aekplakorn W, Afsana K, Aguilar-Salinas CA, Agyemang C. Worldwide trends in body-mass index, underweight, overweight, and obesity from 1975 to 2016: a pooled analysis of 2416 population-based measurement studies in 128. 9 million children, adolescents, and adults. Lancet. 2017;390(10113):2627-42.

19. WHO Global Infobase. Kenya Global School-Based Student Health Survey 2003. WHO 2003. Available https:/apps.who.int/infobase/Indicators.aspx05-316.

20. Kenya's 2016 Report Card on Physical Activity and Body Weight of Children and Youth healthy active kids Kenya/Active healthy kids Canada; 2014. Available https://www.activehealthykids.org/wp-content/uploads/2016/11/ kenya-report-card-long-form-2016.pdf.

21. Muthuri SK, Tremblay MS, Onywera VO. Kenya's 2014 report card on physical activity and body weight of children and youth. Healthy active kids Kenya/active healthy kids Canada; 2014

22. Mwai D, Muriithi M. Non-Communicable diseases risk factors and their contribution to NCD incidences in Kenya. Eur Sci J ESJ. 2015;11(30):268-81.

23. Republic of Kenya. Kenya National Strategy for the Prevention and Control of Non-Communicable Diseases 2015-2020. Nairobi: Ministry of Health Division of Non-communicable Diseases; 2015.

24. Ministry of Health, Kenyan National Bureau of Statistics, W. H. O. (2015). Kenya STEPwise Survey for Non-Communicable Diseases Risk Factors 2015 Report.

25. Bull FC, Maslin TS, Armstrong T. Global physical activity questionnaire (GPAQ): nine country reliability and validity study. J Phys Act Health. 2009;6(6):790-804.

26. Guthold R, Ono T, Strong KL, Chatterji S, Morabia A. Worldwide variability in physical inactivity: a 51-country survey. Am J Prev Med. 2008;34(6):486-94.

27. Ministry of Health, W.H.O, UNDP, World Diabetes Foundation. (2014). Uganda Non-Communicable Diseases Risk Factors Baseline Survey 2014 Report.

28. Hosseinpoor AR, Bergen N, Kunst A, Harper S, Guthold R, Rekve D, d'Espaignet ET, Naidoo N, Chatterji S. Socioeconomic inequalities in risk factors for non communicable diseases in low-income and middle-income countries: results from the world health survey. BMC Public Health. 2012;12(1):912.

29. World Health Organization. STEPS country reports. 2015 [2016-12-19]. 2016. http://www. who. int/chp/steps/reports/en.

30. De Bourdeaudhuij I, Sallis JF, Saelens BE. Environmental correlates of physical activity in a sample of Belgian adults. Am J Health Promot. 2003; 18(1):83-92.

31. Adegoke BO, Oyeyemi AL. Physical inactivity in Nigerian young adults: prevalence and socio-demographic correlates. J Phys Act Health. 2011;8(8): $1135-42$.

32. Trinh OT, Nguyen ND, Dibley MJ, Phongsavan P, Bauman AE. The prevalence and correlates of physical inactivity among adults in $\mathrm{Ho}$ Chi Minh City. BMC Public Health. 2008;8(1):204.

33. Macera CA, Ham SA, Yore MM, Jones DA, Kimsey CD, Kohl HW III, Ainsworth BE III. PEER REVIEWED: Prevalence of Physical Activity in the United States: Behavioral Risk Factor Surveillance System, 2001. Prev Chronic Dis. 2005;2(2)

34. Bauman A, Bull F, Chey T, Craig CL, Ainsworth BE, Sallis JF, Bowles HR, Hagstromer M, Sjostrom M, Pratt M. The international prevalence study on physical activity: results from 20 countries. Int J Behav Nutr Phys Act. 2009;6(1):21

35. Tavares LS, Plotnikoff RC. Not enough time? Individual and environmental implications for workplace physical activity programming among women with and without young children. Health Care Women Int. 2008:29(3):244-81.

36. Parra-Medina D, Messias DK. Promotion of physical activity among Mexicanorigin women in Texas and South Carolina: an examination of social, cultural, economic, and environmental factors. Quest. 2011;63(1):100-17.

37. Omoleke SA. Chronic non-communicable disease as a new epidemic in Africa: focus on the Gambia. Pan Afr. Med. J. 2013;14(1):87.

38. Micklesfield LK, Pedro TM, Kahn K, Kinsman J, Pettifor JM, Tollman S, Norris SA. Physical activity and sedentary behavior among adolescents in rural South Africa: levels, patterns and correlates. BMC Public Health. 2014;14(1):40 
39. Umstattd MR, Wilcox S, Saunders R, Watkins K, Dowda M. Self-regulation and physical activity: the relationship in older adults. Am J Health Behav. 2008;32(2):115-24.

40. Shaw BA, Spokane LS. Examining the association between education level and physical activity changes during early old age. J. Aging Health. 2008; 20(7):767-87.

41. Muthuri SK, Wachira L, Onywera VO, Tremblay MS. Correlates of objectively measured overweight/obesity and physical activity in Kenyan school children: results from ISCOLE-Kenya. BMC Public Health. 2014;14(1):436

42. O'Donovan G, Stensel D, Hamer M, Stamatakis E. The association between leisure-time physical activity, low HDL-cholesterol and mortality in a pooled analysis of nine population-based cohorts. Eur J Epidemiol. 2017;32(7):559-66.

43. Skoumas J, Pitsavos C, Panagiotakos DB, Chrysohoou C, Zeimbekis A, Papaioannou I, Toutouza M, Toutouzas P, Stefanadis C. Physical activity, high density lipoprotein cholesterol and other lipids levels, in men and women from the ATTICA study. Lipids Health Dis. 2003;2(1):3.

44. Enger SC, Herbjørnsen K, Erikssen J, Fretland A. High density lipoproteins (HDL) and physical activity: the influence of physical exercise, age and smoking on HDL-cholesterol and the HDL-/total cholesterol ratio. Scand J Clin Lab Invest. 1977;37(3):251-5.

45. Sobngwi E, Mbanya JN, Unwin NC, Kengne AP, Fezeu L, Minkoulou EM, Aspray TJ, Alberti KG. Physical activity and its relationship with obesity, hypertension and diabetes in urban and rural Cameroon. Int J Obes. 2002; 26(7):1009.

46. Aspray TJ, Mugusi F, Rashid S, Whiting D, Edwards R, Alberti KG, Unwin NC. Essential non-communicable disease health intervention project. Rural and urban differences in diabetes prevalence in Tanzania: the role of obesity, physical inactivity and urban living. Trans R Soc Trop Med Hyg. 2000;94(6):637-44.

47. Assah FK, Ekelund U, Brage S, Mbanya JC, Wareham NJ. Urbanization, physical activity, and metabolic health in sub-Saharan Africa. Diabetes Care. 2011;34(2):491-6.

48. Wilcox S, Castro C, King AC, Housemann R, Brownson RC. Determinants of leisure time physical activity in rural compared with urban older and ethnically diverse women in the United States. J Epidemiol Community Health. 2000;54(9):667-72.

49. Kruger HS, Venter CS, Vorster HH, Margetts BM. Physical inactivity is the major determinant of obesity in black women in the north West Province, South Africa: the THUSA study. Nutrition. 2002;18(5):422-7.

50. GBD 2016 Causes of Death Collaborators. Global, regional, and national age-sex specific mortality for 264 causes of death, 1980-2016: a systematic analysis for the Global Burden of Disease Study 2016. Lancet. 2017; 390(10100):1151-210.

51. GBD 2016 DALYs and HALE Collaborators. Global, regional, and national disability-adjusted life-years (DALYs) for 333 diseases and injuries and healthy life expectancy (HALE) for 195 countries and territories, 1990-2016: a systematic analysis for the Global Burden of Disease Study 2016. Lancet. 2017;390(10100):1260-344.

52. Aadahl M, JØrgensen T. Validation of a new self-report instrument for measuring physical activity. Med Sci Sports Exerc. 2003;35(7):1196-202.

53. Booth ML, Owen N, Bauman A, Gore CJ. Relationship between a 14-day recall measure of leisure-time physical activity and a submaximal test of physical work capacity in a population sample of Australian adults. Res Q Exerc Sport. 1996;67(2):221-7.

54. Ainsworth BE, Haskell WL, Leon AS, Jacobs JD, Montoye HJ, Sallis JF, Paffenbarger JR. Compendium of physical activities: classification of energy costs of human physical activities. Med Sci Sports Exerc. 1993;25(1):71-80.

55. Sallis JF, Saelens BE. Assessment of physical activity by self-report: status, limitations, and future directions. Res Q Exerc Sport. 2000;71(sup2):1-4.

56. Rauh MJ, Hovell MF, Hofstetter CR, Sallis JF, Gleghorn A. Reliability and validity of self-reported physical activity in Latinos. Int J Epidemiol. 1992; 21(5):966-71.

Ready to submit your research? Choose BMC and benefit from:
- fast, convenient online submission
- thorough peer review by experienced researchers in your field
- rapid publication on acceptance
- support for research data, including large and complex data types
- gold Open Access which fosters wider collaboration and increased citations
- maximum visibility for your research: over 100M website views per year
At BMC, research is always in progress.
Learn more biomedcentral.com/submissions

